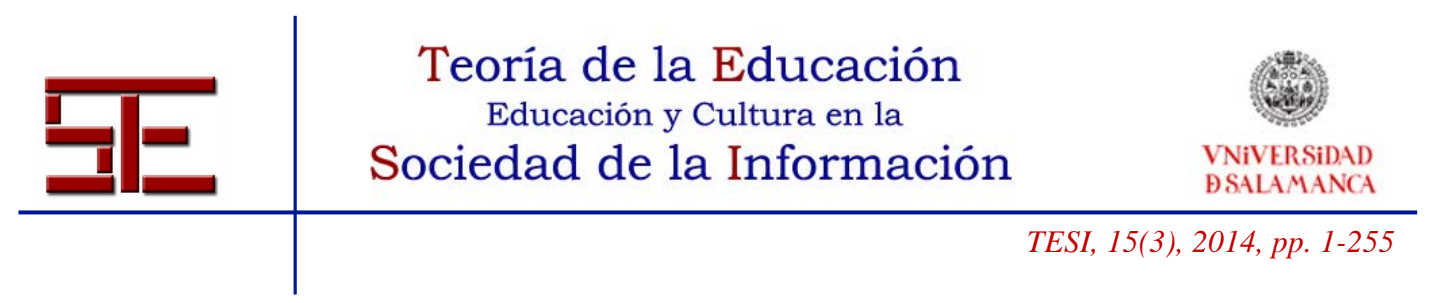

\title{
MODELO DE PRESENTACIÓN DE MATERIAL DE ESTUDIO MEDIANTE EL ANÁLISIS DE ESTÁNDARES DE CALIDAD Y USABILIDAD PARA $E$ - LEARNING
}

\section{Christian David \\ QUINTERO \\ GUERRERO}

Universidad Militar

Nueva Granada, Colombia

christian.quintero@unimilitar.edu.co

\author{
Raúl Andrés \\ GUTIÉRREZ \\ VILLARRAGA \\ Universidad Militar \\ Nueva Granada, Colombia \\ raulguti90@gmail.com
}

\author{
Jorge Augusto \\ JARAMILLO MUJICA \\ Universidad Militar \\ Nueva Granada, Colombia \\ jorge.jaramillo@unimilitar.edu.co
}

\section{Resumen:}

Uno de los principios de e-learning como modelo de aprendizaje emergente se logra a través de la presentación de contenido de calidad, lo que implica la construcción de material de estudio partiendo de parámetros relacionados a la presentación, contenido temático y usabilidad; esto con el fin de obtener un apoyo en los procesos educativos virtuales. Este trabajo presenta una propuesta enmarcada dentro de este contexto, donde se parte del análisis de diferentes estándares y normas de calidad dirigidos al campo de la usabilidad, que establecen principios orientados al diseño centrado al usuario en el desarrollo de aplicaciones multimedia contribuyendo al mejoramiento de la experiencia de usuario, para que de esta manera se logre mantener líneas de producción de contenidos, que sean competitivos y se ajusten a los modelos de calidad exigidos a las instituciones inmersas en la virtualidad.

Como resultado de la investigación, se realiza un análisis de estándares de calidad y usabilidad, los cuales se presentan mediante el análisis del modelo de un software educativo PLISE, con base en parámetros de calidad establecidos por la institución, dando soporte a los programas virtuales que se desarrollan en el centro educativo.

Palabras clave: material de estudio, e-learning, estándares, usabilidad, virtualidad.

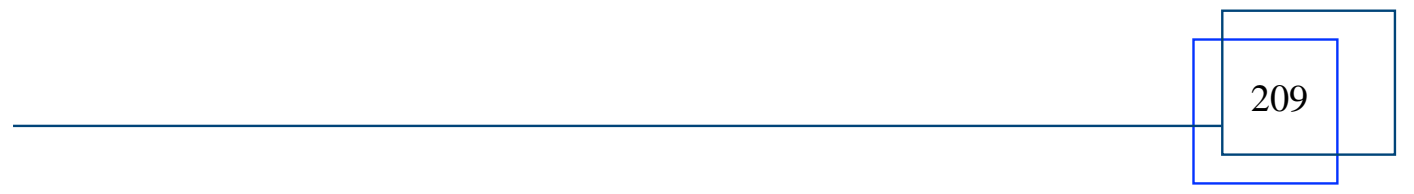




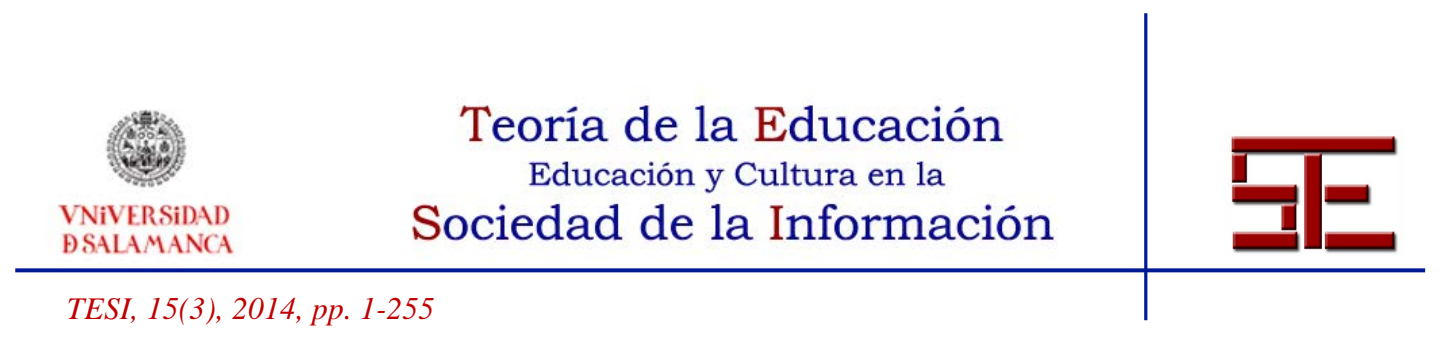

\title{
E-CONTENT PRESENTATION MODEL BASED OF QUALITY AND USABILITY STANDARD FOR E-LEARNING
}

\begin{abstract}
:
One of the principles of e-learning as a model of emergent learning is achieved through the presentation of quality content, which involves the construction of e-content based on parameters related to the presentation, subject content and usability allow to obtain support into virtual educational processes. This article presents a proposal into this context, is based on analysis of different quality standards and layout handle the area of usability, in focus of principles oriented to user design in the development of multimedia applications helping to improve the user experience, and thus this way keep the content production lines which are competitive and adjust the required quality models to connection in virtual institutions.

As a result of the investigation an analysis of quality and usability standards is made, these are presented by the analysis of educational software model named PLISE, based on quality standards established by the institution, giving support of the virtual programs developed at Institutions.
\end{abstract}

Key words: virtual learning objects, e-learning, international standards, multimedia contents. 


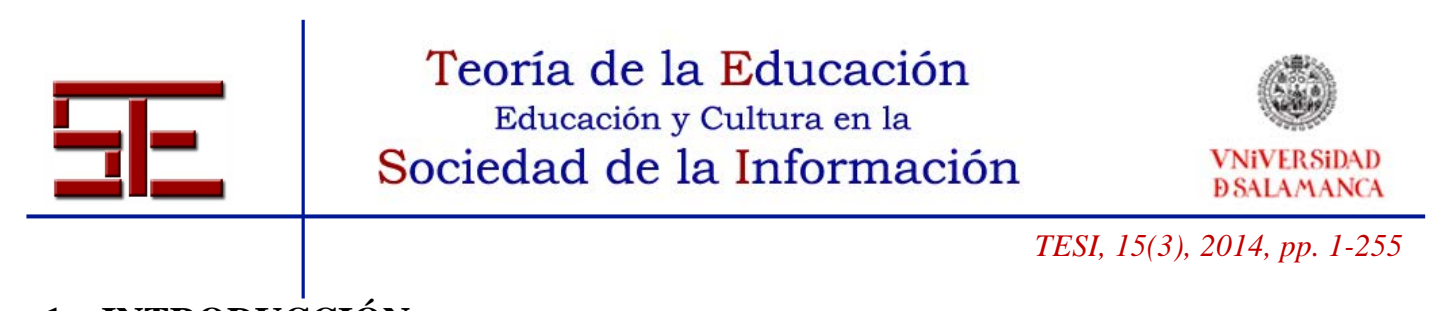

\section{INTRODUCCIÓN}

Como parte de los procesos de globalización e internacionalización en los sistemas económicos y políticos, las instituciones se han visto afectadas en el sentido de tener que ajustarse a determinados modelos de competitividad, que les implica el cambio de sus actividades y prácticas comerciales. La escuela como institución ha sido permeada en su esencia en lo organizativo, educativo y tecnológico.

Prueba de ello son la búsqueda en mejorar su calidad, posicionamiento, impacto y excelencia, al verse ubicadas en listados de posicionamiento que como el "Ranking Mundial de Universidades en la Web" del Laboratorio de Cibermetría, que pertenece al CSIC (Consejo Superior de investigaciones Científicas, CSIC, España), el mayor centro nacional de investigación de España, permite visualizar de forma rápida la posición de nuestras universidades y su sitio en el mundo ${ }^{4}$. Este Ranking de Universidades, proporciona la clasificación más completa y actualizada de instituciones de educación superior de todo el mundo.

Según Castells (citado por Duart \& Lupiañez, 2005), afirma que:

En este nuevo contexto, la universidad tiene un papel fundamental, como elemento central de nuestra sociedad y nuestra economía. Es "la" institución de la sociedad red. Pero la universidad de hoy no debe ser una institución anclada en valores y formas del pasado, sino que debe responder a nuestras necesidades actuales en un nuevo contexto social y tecnológico que tiene en internet su "espacio natural".

Es así como los procesos de formación hoy en día, deben estar fundamentados en modelos como el e-learning, b-learning o m-learning, que implican necesariamente la elaboración, adaptación o selección de contenidos educativos de alta calidad. Estas modalidades educativas han estado creciendo de una forma significativa debido a la creciente demanda en educación, haciendo necesario revisar aquellos parámetros que ayuden a diseñar mejores contenidos educativos, soportados en criterios pedagógicos y didácticos con altos niveles de usabilidad y orientados a la educación globalizada, que permitan ser utilizados y adaptados a innovaciones tecnológicas futuras. Esto implica la construcción de materiales de estudio (e-content), sustentados con criterios de diseño instruccional, que fomenten la consulta, estudio, evaluación del aprendizaje, el acceso y comprensión de los materiales.

Es muy importante establecer una estructura y organización general de presentación de los contenidos educativos y mantener una homogeneidad en las plataformas de soporte del aprendizaje, para que así el estudiante logre una optimización en su tiempo de estudio, un orden de lectura y comprensión de los materiales y que esto favorezca el método de estudio particular que se asuma en determinado momento. A su vez, los materiales en su esencia, deben ser autosuficientes y para este fin se deben organizar bajo una estructura funcional que permita una estrategia de organización de la información educativa, cuyo objetivo principal es el convertirse en apoyo directo del

\footnotetext{
${ }^{4}<$ http://www.webometrics.info/es/Latin_America_es $>$.
} 


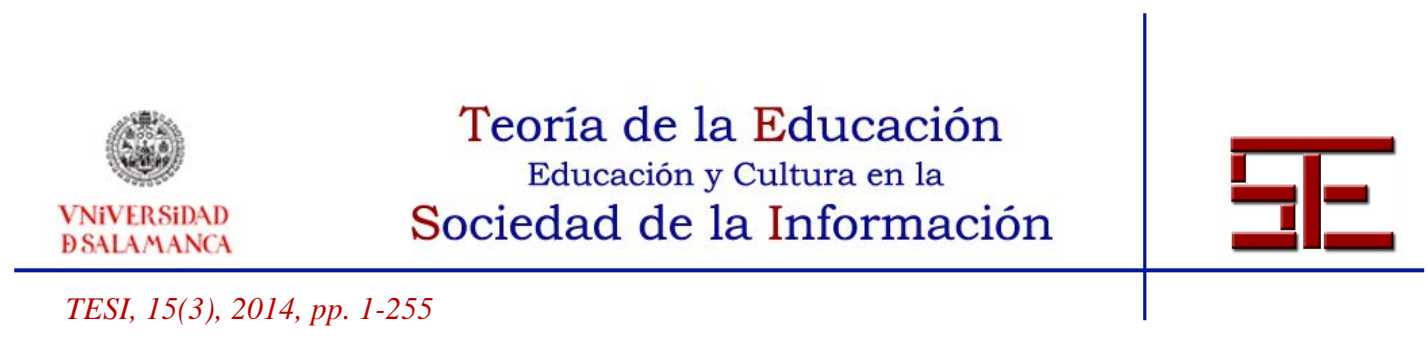

proceso de enseñanza-aprendizaje y poder acompañar en gran medida, la acción docente en su gestión de dirección y asesoría.

\subsection{Material de estudio para una educación globalizada (e-content)}

Con las modalidades del e-learning, se están presentando nuevas formas de pensar sobre el aprendizaje a través del uso de tecnologías que facilitan procesos de mejora del desempeño, en donde las personas pueden aprender de muchas formas, teniendo acceso a contenidos bien diseñados y estructurados. Si se piensa el aprendizaje con estas nuevas alternativas, será más fácil ver las opciones para mejorar el desarrollo del estudiante. Bajo modelos tradicionales de la enseñanza, los docentes llegan al salón de clases con su conocimiento a impartirlo a un grupo de estudiantes, bajo los nuevos esquemas del aprendizaje y particularmente con estrategias de uso tecnológico como apoyo a las labores docentes, se necesitan materiales previamente elaborados y preparados, resultado de una actividad institucional seria y organizada. De esto depende en gran parte el éxito de los programas formativos en la virtualidad. (Duart \& Lupiañez, 2005, pp. 2, 10).

Es así como en las instituciones educativas se vienen configurando entornos tecnológicos para el aprendizaje, los cuales están soportados bajo cuatro pilares fundamentales, la información, la comunicación, la cooperación y la administración (Duart \& Lupiañez, 2005, p. 13). Bajo el primero, se estructura toda la información que el estudiante necesite para el desarrollo de su acción formativa y, como parte de este, cabe mencionar la importancia que tiene plantear modelos organizados en la construcción de materiales educativos.

En términos generales, un material educativo estructurado y adecuadamente diseñado, debe caracterizar unos elementos fundamentales, compuestos de: una presentación o introducción al tema, los objetivos o competencias del aprendizaje del módulo, el desarrollo temático, el cual debe utilizar intensivamente contenidos informativos multimediales, actividades de control que faciliten el repaso y reafirmación de conceptos, componentes de contextualización como un resumen y glosario de términos, más unas autoevaluaciones. El conjunto de estos componentes permite la organización de la información bajo un esquema de relación de los contenidos y material multimedia. En la Figura 1, se presenta el diagrama general de organización de los diferentes componentes mencionados.

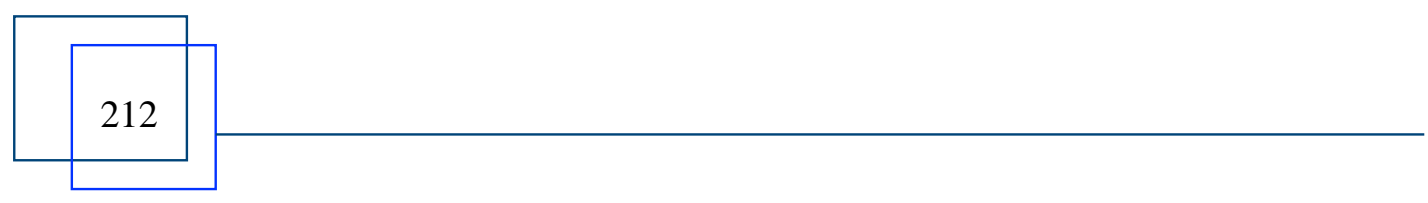




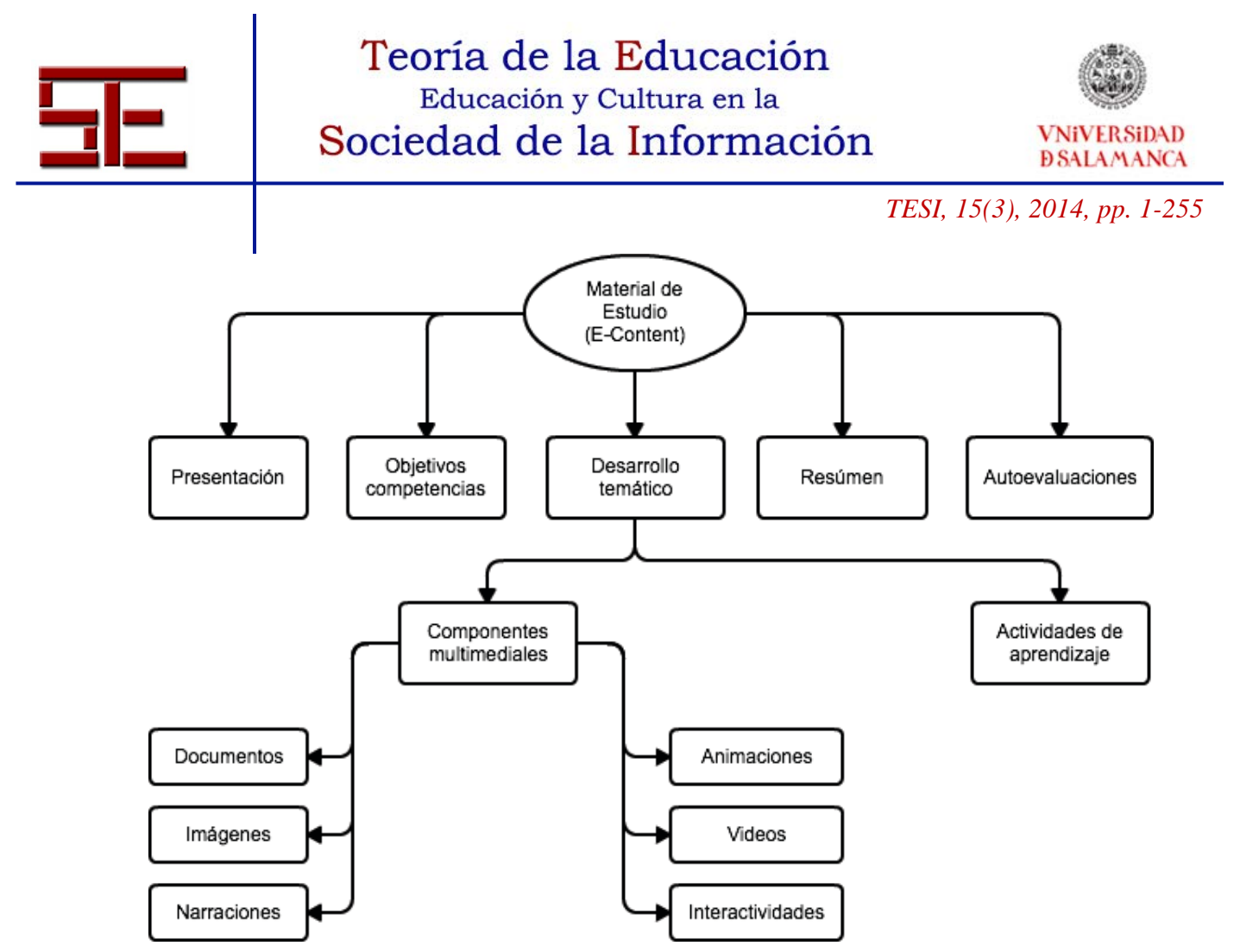

Figura 1. Diagrama de estructuración de componentes fundamentales de un material educativo electrónico.

Es fundamental mencionar la importancia que tiene la calidad en los contenidos producidos, en donde la mediación de un diseñador instruccional enfoca desde la autoría el desarrollo bajo un modelo educativo y didáctico para ser presentado al estudiante. Es a través de un modelo de producción de contenidos educativos (Nova, Jaramillo, \& Quintero, 2012), que se intenta asegurar la calidad científica, pedagógica y tecnológica de un contenido autoformativo, el cual se enmarca bajo una serie de etapas.

El primer paso es asegurar un adecuado entendimiento de desarrollo técnico, para lo cual se realiza una inducción al experto en contenidos, en el tema técnico del lenguaje informático y pedagógico pertinente, para que pueda generar en la forma adecuada los contenidos. El proceso termina con la elaboración de los objetos multimediales que conformarán el material de estudio. En la figura 2, se presenta el modelo general de construcción de contenidos en el cual la función central está a cargo del integrador, quien recoge de los otros actores del proceso, los diferentes componentes para integrarlos, organizarlos y estructurarlos. 

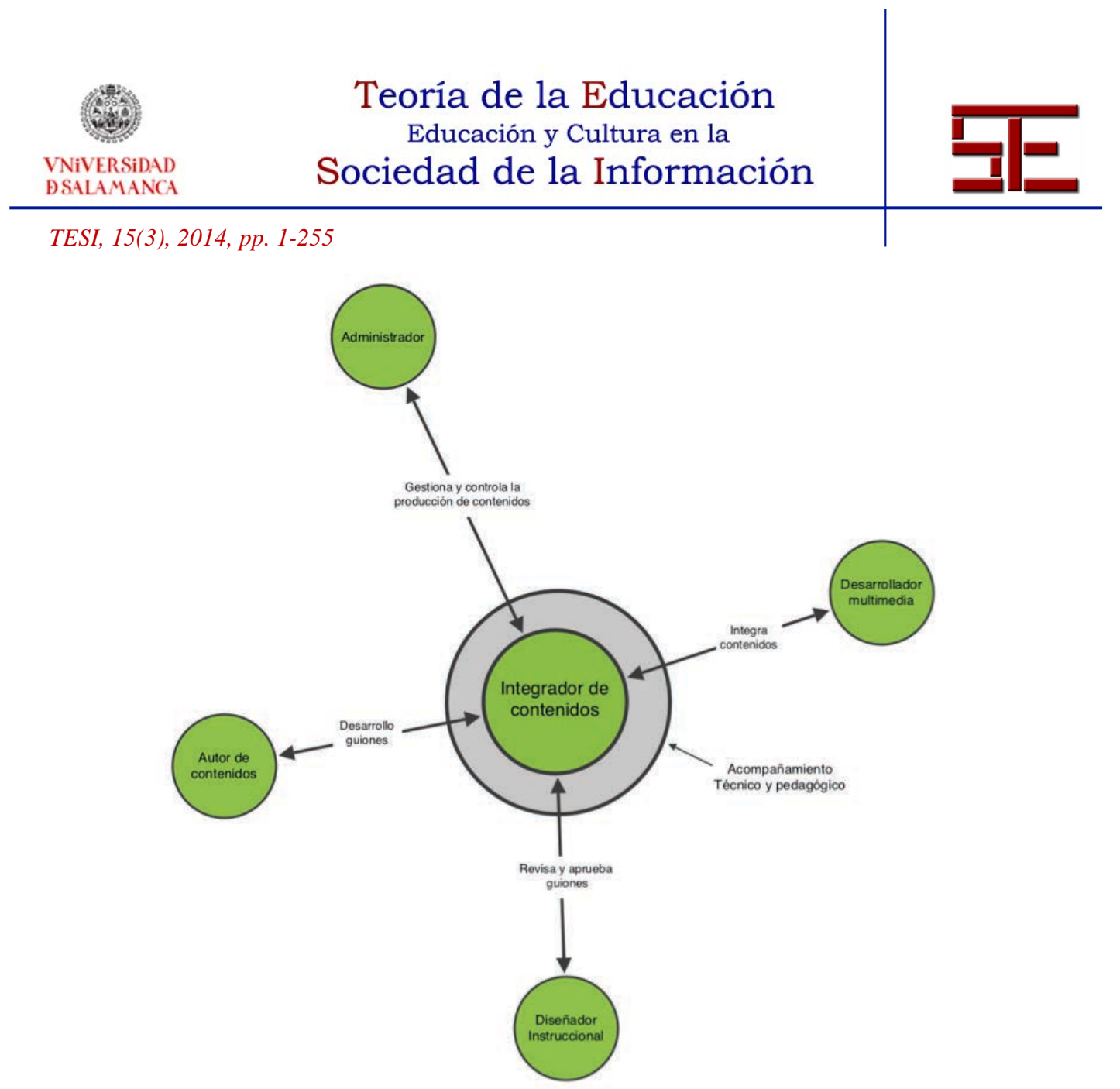

Figura 2. Estructura de construcción de contenidos.

\subsection{Usabilidad en productos interactivos}

La usabilidad en la actualidad más que un concepto relacionado a la facilidad de uso de un producto, abarca el estudio de otras características, como son el diseño y funcionamiento de un interfaz de usuario, con el objetivo de mejorar la experiencia de usuario a través de la comprensión de las necesidades que los clientes quieren satisfacer y de la adaptación del producto a sus modelos mentales.

Para entender mejor este concepto y conocer qué es lo que se requiere analizar en un producto de software, la Organización Internacional para la Estandarización (ISO, "International Standarization Organization") propone dos definiciones de usabilidad desde dos enfoques diferentes (Bevan, 1999):

La norma ISO/IEC 9126 (1991), "la usabilidad se refiere a la capacidad de un software de ser comprendido, aprendido, usado y ser atractivo para el usuario, en condiciones

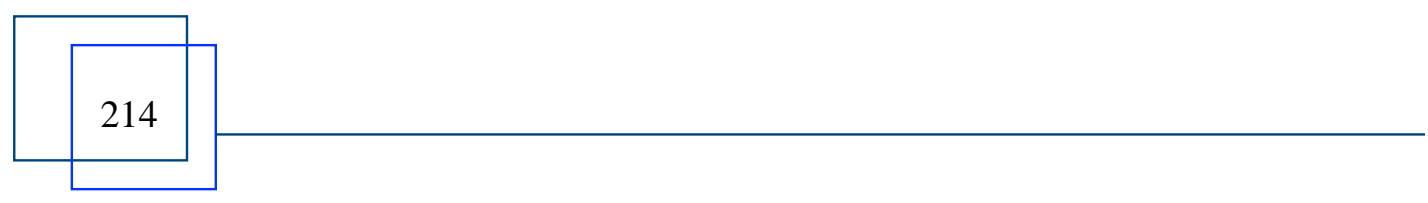




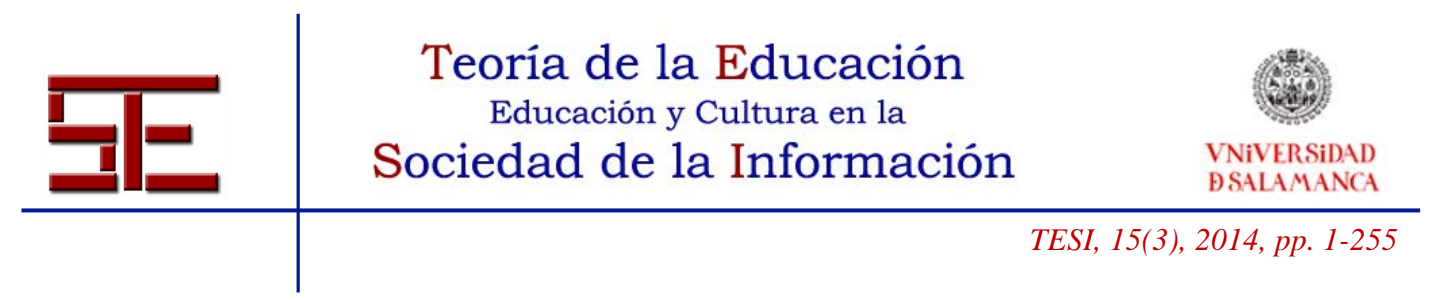

específicas de uso". Esta definición se centra en el conjunto de características del producto, que le otorgan su aptitud para satisfacer las necesidades expresadas o implícitas por parte del usuario, entre las que se encuentran portabilidad, facilidad de uso, funcionalidad y fiabilidad por mencionar algunas. Ahora, la norma ISO 9241-11 (1998) define usabilidad como, "La medida en la que un producto puede ser usado por determinados usuarios para conseguir objetivos específicos con efectividad, eficiencia y satisfacción en un contexto de uso especificado". Este enfoque se centra en la medición de calidad de uso a través de tres aspectos claves: efectividad, eficiencia y satisfacción, es decir, como el usuario realiza tareas específicas en escenarios específicos con éxito.

La usabilidad es una cualidad bastante abstracta como para ser medida en una sola dimensión, y su concepción implica necesariamente la relación múltiples componentes los cuales están relacionados con los siguientes cinco atributos, según lo señala (Nielsen, 1993, p. 26):

$\checkmark$ Capacidad de aprendizaje: La aplicación debe ser sencilla de aprender, permitiendo al usuario tomar contacto rápido con el sistema.

$\checkmark$ Eficiencia en el uso: Una vez que el usuario ha aprendido a utilizar el sistema, podrá lograr un alto grado de productividad al utilizarlo.

$\checkmark$ Facilidad de memorizar: La aplicación debe ser muy fácil de recordar en su uso, luego de un determinado tiempo que tarda el usuario en volver a utilizarla.

$\checkmark$ Tolerante a errores: Esta característica describe la tolerancia a fallas, es decir que la aplicación soporte posibles errores cometidos por parte del usuario y que la misma aplicación pueda recuperarse y así mismo aquellos errores irrecuperales no deben presentarse.

$\checkmark$ Satisfacción: Describe que tan agradable o sencillo le ha parecido al usuario realizar las diferentes actividades al interior de la aplicación y si a éste le ha gustado.

Todos estos conceptos son incorporados de una u otra forma, en los parámetros establecidos en la norma de estándares de calidad, presentados a continuación.

\subsubsection{Estándares institucionales hacia la calidad en los programas académicos en la modalidad a distancia}

Las características que permiten construir programas académicos de calidad en la metodología a distancia se fundamentan bajo una estructura curricular flexible que posibilite la organización de los cursos, las estrategias pedagógicas y comunicativas y los ambientes o escenarios de aprendizaje adecuados para el desarrollo de las competencias esperadas.

El programa de educación a distancia deberá contar con recursos y políticas 


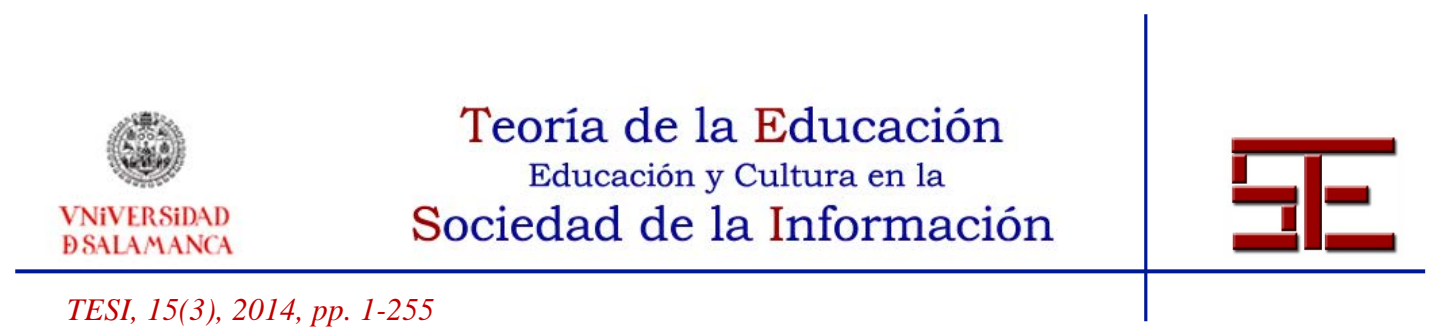

institucionales que permitan el desarrollo de contenidos, que garanticen su permanente actualización frente a los cambios metodológicos y tecnológicos, y así lograr atender estas exigencias, no solamente es importante que la institución educativa disponga de la tecnología necesaria para que los estudiantes puedan acceder a estos recursos, sino prestar especial atención a todos aquellos parámetros que implican la construcción de contenidos con calidad.

\subsubsection{Estándares y normas sobre Interacción Humano-Máquina (HCI, "Human-} Computer Interaction”), usabilidad y su relación con el diseño de interacción

El objetivo del $\mathrm{HCI}^{5}$ es generar ambientes con una mayor producción de tareas que rodean los sistemas informáticos para uso humano, por lo que se han desarrollado a nivel internacional una serie de normas que establecen métricas de uso, seguridad y funcionalidad que aseguran el buen funcionamiento del software. En la Tabla 1, se presentan las normas relacionadas a este tema (UsabilityNet, 2006):

\begin{tabular}{|l|l|}
\hline Norma & Descripción \\
\hline ISO/IEC 9126-1 & $\begin{array}{l}\text { Ingeniería de software - Calidad de producto - Modelos de } \\
\text { calidad. }\end{array}$ \\
\hline ISO/IEC TR 9126-4 & $\begin{array}{l}\text { Ingeniería de software - Calidad de producto - Calidad en } \\
\text { métricas de uso. }\end{array}$ \\
\hline ISO 9241-11 & Guías en usabilidad. \\
\hline ISO/IEC TR 9126-2 & $\begin{array}{l}\text { Ingeniería de software - Calidad de producto - Métricas } \\
\text { externas. }\end{array}$ \\
\hline ISO/IEC TR 9126-3 & $\begin{array}{l}\text { Ingeniería de software - Calidad de producto - Métricas } \\
\text { internas. }\end{array}$ \\
\hline ISO 9241 & $\begin{array}{l}\text { Requisitos ergonómicos para oficinas con terminales } \\
\text { visuales. }\end{array}$ \\
\hline ISO 11064 & Diseño ergonómico para centros de control. \\
\hline
\end{tabular}

5 HCI "Es una disciplina relacionada con el diseño, evaluación, desarrollo y estudio de los fenómenos que rodean los sistemas informáticos para uso humano", ACM SIGCHI.

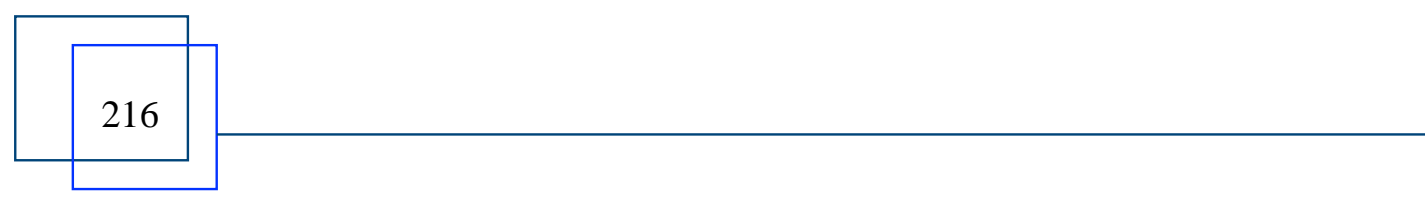




\begin{tabular}{|c|c|}
\hline 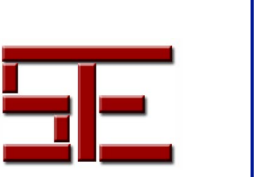 & $\begin{array}{l}\text { Teoría de la Educación } \\
\text { Educación y Cultura en la } \\
\text { Sociedad de la Información }\end{array}$ \\
\hline & TESI, 15(3), 2014, pp. 1-255 \\
\hline ISO 14915 & Ergonomía de software para interfaz multimedia. \\
\hline IEC TR 61997 & $\begin{array}{l}\text { Guías de interfaz de usuario en equipos multimedia de uso } \\
\text { general. }\end{array}$ \\
\hline ISO/IEC 18019 & $\begin{array}{l}\text { Guías para el diseño y preparación de documentación de } \\
\text { software de usuario. }\end{array}$ \\
\hline ISO 9241-210 & $\begin{array}{l}\text { Diseño de procesos centrados en el usuario. Antes llamado } \\
\text { ISO } 13407 \text {. }\end{array}$ \\
\hline ISO TR 16982 & Métodos de soporte de diseños centrados en usuarios. \\
\hline ISO TR 18529 & Procesos descriptivos de vida de producto. \\
\hline ISO 10075-1 & $\begin{array}{l}\text { Principios ergonómicos de carga mental, términos y } \\
\text { definiciones. }\end{array}$ \\
\hline ISO DTS 16071 & Guía de accesibilidad en interfaz de usuario. \\
\hline
\end{tabular}

Tabla 1. Normas y estándares relacionados con HCI y usabilidad.

En esta sección se centra en el estándar de calidad ISO 14915, que se ocupa de la ergonomía de software para interfaces de usuario multimediales, que corresponde al tema de interés y de valoración en este artículo, el cual se divide en tres partes:

Parte 1: Principios del diseño y estructura: Establece los principios de diseño para interfaces de usuarios multimedia y proporciona un marco para manejar las diversas consideraciones implicadas en su diseño. Analiza las interfaces de usuario que incorporan, integran y sincronizan diversos medios como texto, gráficos o imágenes y medios dinámicos como audio, animación, video o medios relacionados a otras modalidades sensoriales.

Parte 2: Control y navegación multimedia: Ofrece recomendaciones y requerimientos para el diseño de interfaces de usuario multimediales con respecto a la organización del contenido, navegación y características de reproducción de medios.

Parte 3: Combinación y selección de medios: Ofrece recomendaciones para el diseño, selección y combinación de interfaces de usuario interactivas que integran y sincronizan diversos medios. Esto incluye medios como audio, animación, vídeo y otros.

\subsubsection{Principios de diseño para aplicaciones multimedia}




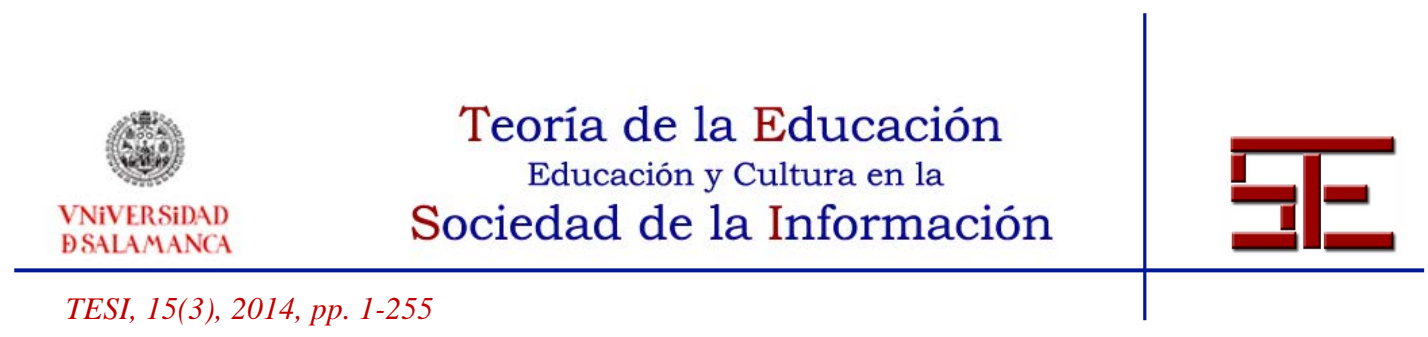

El continuo avance tecnológico y la fuerte competencia del mercado relacionado al desarrollo de software de calidad, han provocado un cambio en cuanto a la definición de aplicaciones multimedia. En principio en este tipo de aplicaciones lo primordial era la estructura (organización interna de los datos) por encima de la vista (percepción de los datos que llegan al usuario), con el tiempo y con la creación de los estándares anteriormente mencionados se han establecido parámetros generales y se han generado teorías encargadas de estudiar la interacción Humano-Máquina, donde se enfatiza en la vista como un conjunto de recursos imágenes, textos, sonidos utilizados como medio para presentar la información y que permiten la interacción del usuario con el computador.

Bajo estos parámetros, se han postulado una serie de principios que son aplicables al diseño y concepción de ambientes con niveles de usabilidad específicos, lo cual ha implicado aspectos de motivación del estudiante para la interacción permanente con el material interactivo y así lograr una experiencia de usuario satisfactoria.

(Bauzá, 1997) propone un conjunto de principios orientados al diseño de aplicaciones multimedia, los cuales permiten analizar la propuesta de usabilidad de un producto de software educativo.

Si estos principios son adaptados al diseño y estructuración de aplicaciones multimedia centradas en el usuario, se logrará obtener un producto final de calidad. A continuación se presentan los principios establecidos para poder lograr este objetivo:

$\checkmark$ El principio de la múltiple entrada consiste en la efectividad del mensaje transmitido desde una aplicación, en la medida que se combinen en forma complementaria los diferentes canales de comunicación como texto, imagen y sonido.

$\checkmark$ El principio de la interactividad, rompe radicalmente con la linealidad, con el único objetivo de reforzar el mensaje que se quiere transmitir.

$\checkmark$ Desde el principio de la libertad, se presentan unos contenidos bien estructurados, para hacer parecer como un esquema de total control de acceso y libertad de movimiento dentro del mismo.

$\checkmark$ Con el principio de retroalimentación se presenta una comunicación bidireccional, con la capacidad de generar respuestas acordes a un comportamiento particular.

$\checkmark$ El principio de vitalidad dice que toda pantalla debe dar la sensación de estar viva, con capacidades de estimulación visual y auditiva.

$\checkmark$ El principio de necesidad menciona que no deben producirse aplicaciones multimedia por gustos personales o por estar a la moda, sino porque realmente

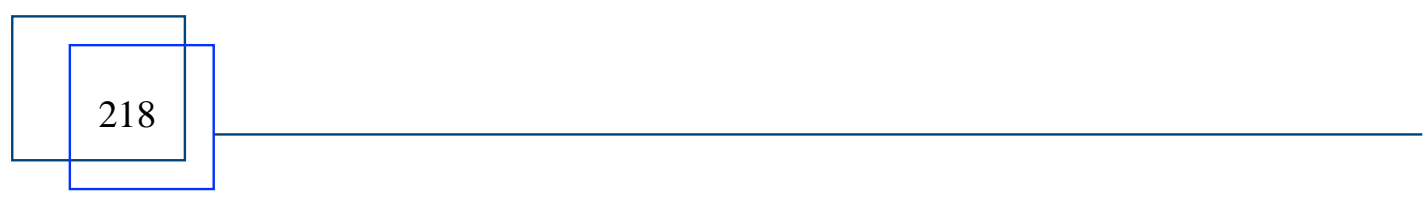




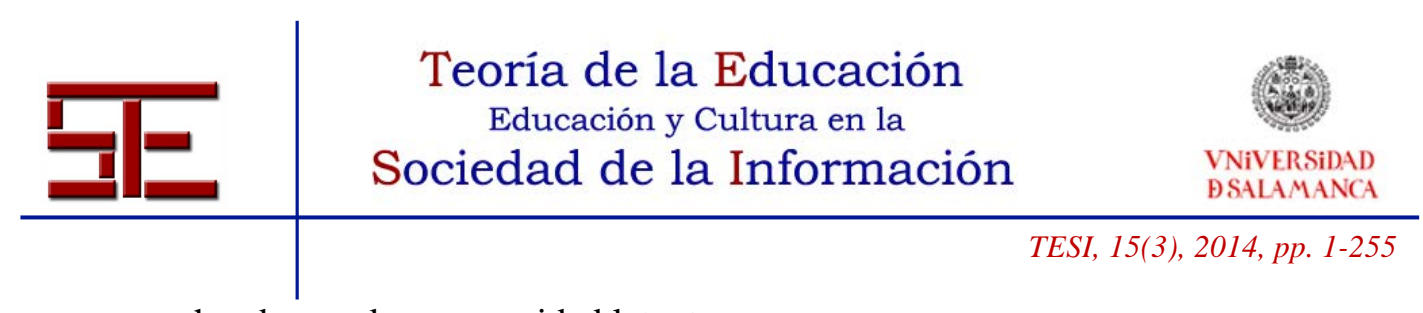

se ha observado su necesidad latente.

$\checkmark$ El principio de atención busca lograr que el usuario se mantenga expectante, consiguiendo una actitud sostenida ante la aplicación.

$\checkmark$ Según el principio de unicidad, el usuario debe percibir la aplicación como un producto homogéneo y así lograr la percepción global de su funcionamiento y estructura.

$\checkmark$ El principio de ergonomía establece que una aplicación debe evitar confusiones y errores, en la utilización que el usuario realice de la aplicación.

$\checkmark$ El principio de uniformidad funcional establece que el sistema debe poseer pautas o reglas de funcionamiento claras uniformes.

○ Uniformidad tipográfica.

○ Interacción hombre-máquina regular.

- Zonas con funciones fijas.

○ Uniformidad icónica.

\section{CONTEXTO}

La $\mathrm{OCDE}^{6}$, en el 2001, realizó un ejercicio de construcción de alternativas teóricas o ideales de futuro para la educación y dentro de este análisis, uno de los escenarios propuestos corresponde al del mercado en el cual se menciona que las instituciones son cada vez más autónomas y compiten entre sí, bajo un marco fuerte de presión por la innovación (Brunner, 2003).

Estos procesos de innovación han implicado que la mayoría de instituciones de educación superior hayan empezado la transición de modelos de aprendizaje tradicional hacia modelos con fuerte soporte de tecnologías como el e-learning, teniendo que diseñar e integrar ambientes virtuales de aprendizaje, con el fin de optimizar los tiempos y lograr una mayor cobertura en sus programas educativos.

Lo anterior puede evidenciarse en las estadísticas reveladas por la empresa especializada en e-learning, redes sociales y gestión del conocimiento, e-ABC en la encuesta realizada entre septiembre y diciembre de 2010, que en materia de la implementación de proyectos con el uso de las Tecnologías de la Información y la Comunicación (TIC), el $89 \%$ de las universidades latinoamericanas están implementando proyectos de e-learning y el $76 \%$ opta por proyectos en b-learning (America Learning Media, 2010).

\footnotetext{
${ }^{6}$ Organización para la Cooperación y el Desarrollo Económicos.
} 


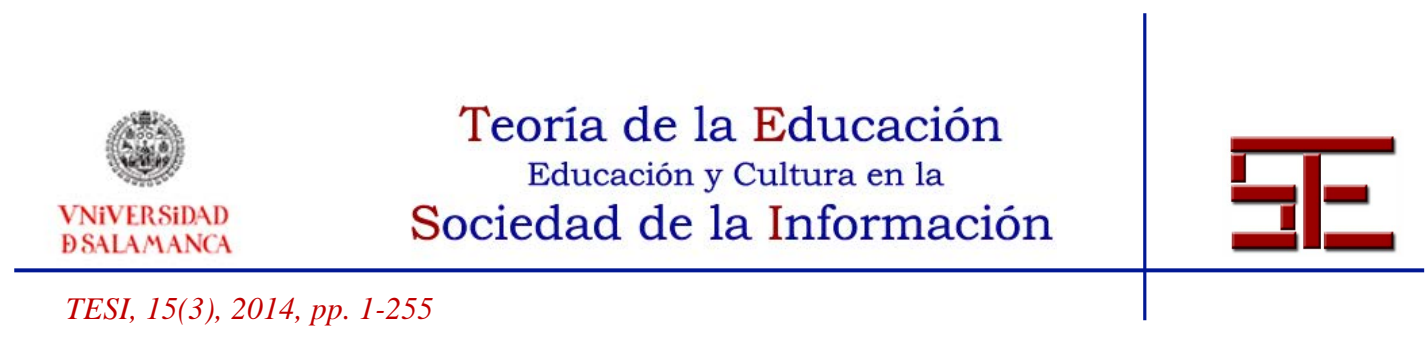

Bajo este contexto, las instituciones educativas deben innovar en la incorporación de parámetros de calidad a los modelo educativos que hayan diseñado e implementado, con el fin estandarizar, por ejemplo, la construcción y visualización de los materiales de estudio, definir procesos y procedimientos dentro de sus propios sistemas de gestión de la calidad y la administración de sus esquemas educativos y administrativos en general.

\subsection{Descripción del modelo de software educativo a evaluar}

El objetivo de este proyecto es precisamente el de realizar una valoración en la aplicación de estándares de calidad bajo el concepto de usabilidad, a un producto de software que viene en proceso de implementación desde su primera versión en 2001, el cual se ha convertido en un modelo estandarizado para la distribución de contenidos educativos en la Universidad Militar Nueva Granada para la modalidad de educación a distancia.

Este producto de software educativo se ha diseñado bajo un modelo plantilla multimedia interactiva, a través de la cual se pueden visualizan los objetos multimediales que conforman una asignatura particular. Estos contenidos son construidos por un equipo de expertos, entre los que se ubican diseñadores gráficos, editores de audio y video, locutores, animadores 3D y 2D, entre otros. El fin es poder ofrecerle a los estudiantes de la modalidad virtual, una herramienta particular de visualizar los contenidos de estudio de forma estructurada, al interior de una interfaz gráfica y un modelo de navegación estándar. A este visor de contenidos, se le ha denominado PLISE (Plataforma Interactiva de Software Educativo).

La propuesta gráfica de este producto permite el acceso a diversos canales de comunicación traducidos en contenidos temáticos de texto, audios, animaciones, videos, imágenes, actividades e interactividades. Los objetos multimedia, podrán ser presentados desde enlaces definidos en el texto de la ventana principal o desde una barra de acceso a medios. En la Figura 3, se ilustra el modelo general de presentación de contenidos desde PLISE. 

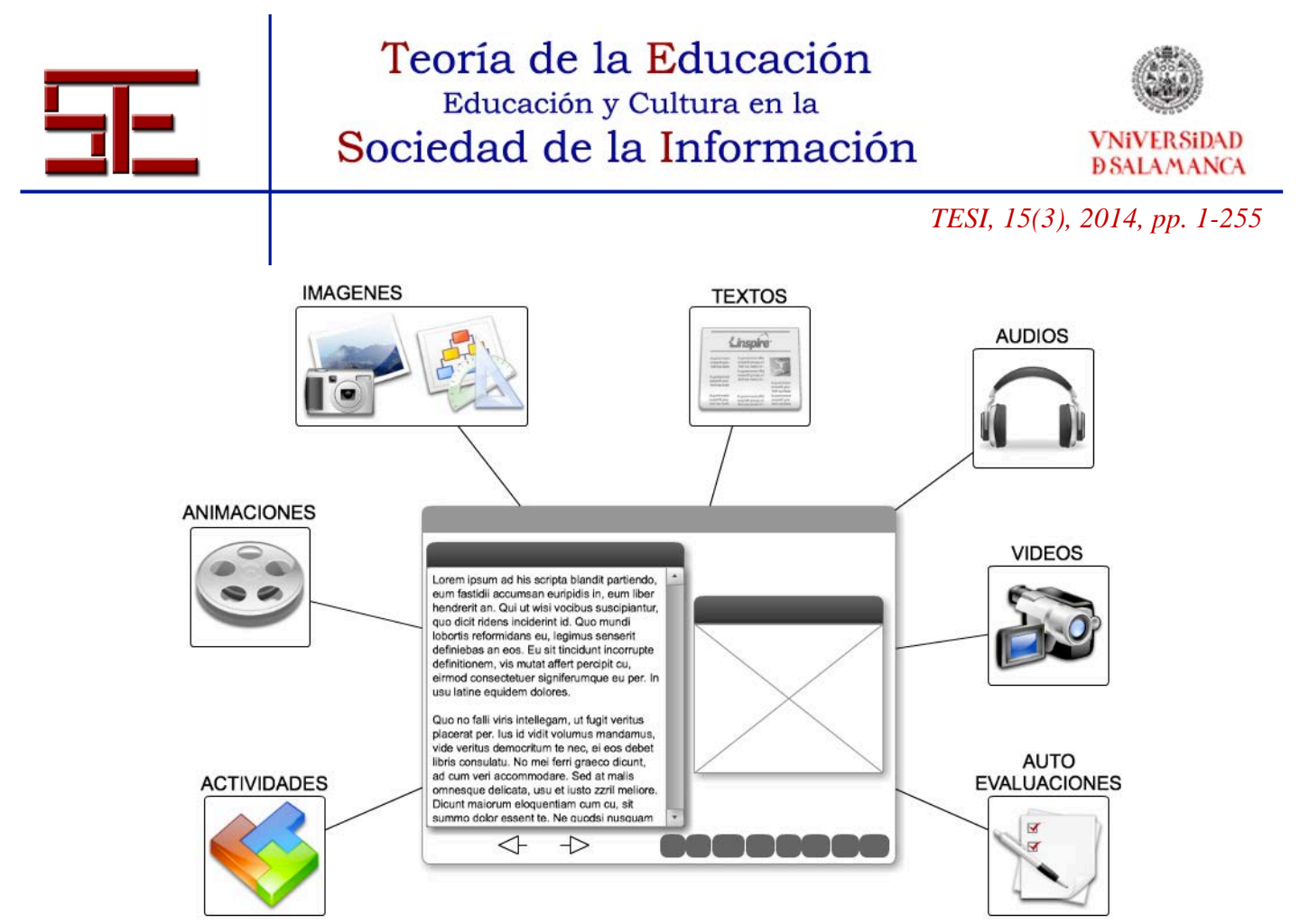

Figura 3. Modelo de presentación de contenidos de PLISE.

En la Figura 4, se presenta la interfaz gráfica del visor de contenidos - PLISE, la cual muestra, a manera de ejemplo, los contenidos de un tema particular relacionado con los derechos humanos. En la interfaz se pueden observan los siguientes componentes:

$\checkmark$ Ventana principal de texto - (A): Es el espacio reservado en la pantalla, en donde se presenta el componente de lectura principal para cada tema. Este texto presenta una información que contiene la descripción más importante por cada uno de los temas en estudio, tal como ha sido concebida por el experto temático. Desde este contenido textual se pueden enlazar diferentes objetos multimedia como textos, imágenes, animaciones, videos, entre otros, que van acorde al flujo de la lectura, principalmente para ampliarlo y complementarlo.

$\checkmark$ Ventana de presentación de medios - (B): Es el espacio en donde se reproducen los objetos multimedia complementarios al tema presentado que han sido diseñados para cada pantalla o tema, como: narraciones, imágenes, textos, videos, animaciones, interactividades o actividades de repaso. Estos contenidos se cargan desde la barra de acceso a medios.

$\checkmark$ Barra de acceso a medios - (C): Espacio en la interfaz gráfica, en donde se presentan los diferentes botones de acceso a los objetos digitales multimediales, que complementan el tema actual en estudio. Desde esta barra se presentan las narraciones, fotografías, gráficos, animaciones, videos, interactividades, actividades de repaso y autoevaluaciones. Es importante resaltar que la concepción y orientación de estos medios, desde la producción en autoría, son

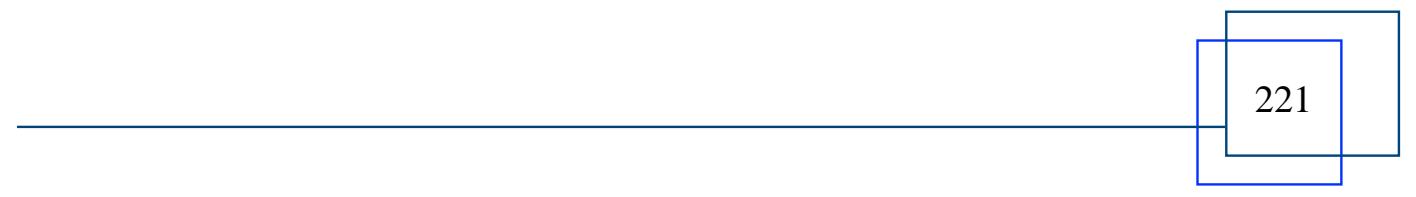




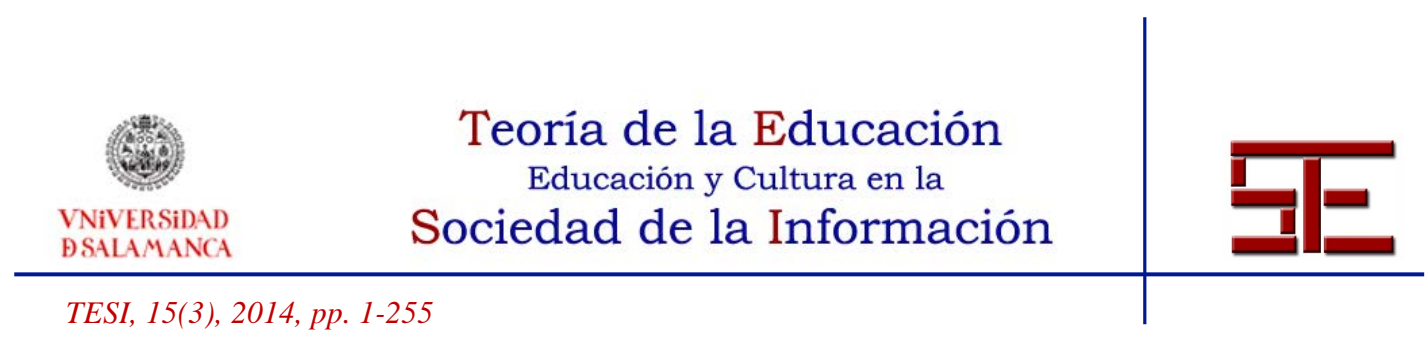

complementarios y permiten reforzar el tema presentado.

$\checkmark$ Navegación secuencial - (D): En la parte inferior de la ventana de texto, se disponen los botones de navegación secuencial, que permiten al usuario, desplazarse tema por tema, indicando la posición actual y el total de temas dispuestos en el objeto de aprendizaje. En la medida que el estudiante avance o retroceda, la interfaz gráfica activa o desactiva en la barra de acceso a medios, los objetos multimedia dispuestos para el tema respectivo.

$\checkmark$ Mapa de temas - (E): En el menú emergente del costado izquierdo, se tiene a disposición un diagrama denominado mapa de temas, el cual le presenta al estudiante de forma gráfica los contenidos incluidos en el objeto virtual de aprendizaje.

$\checkmark$ Tabla de contenido - (F): Es otro menú emergente que presenta, en forma secuencial, los temas desarrollados en el objeto virtual de aprendizaje. Desde aquí, se puede navegar en forma directa a cualquiera de los temas listados.

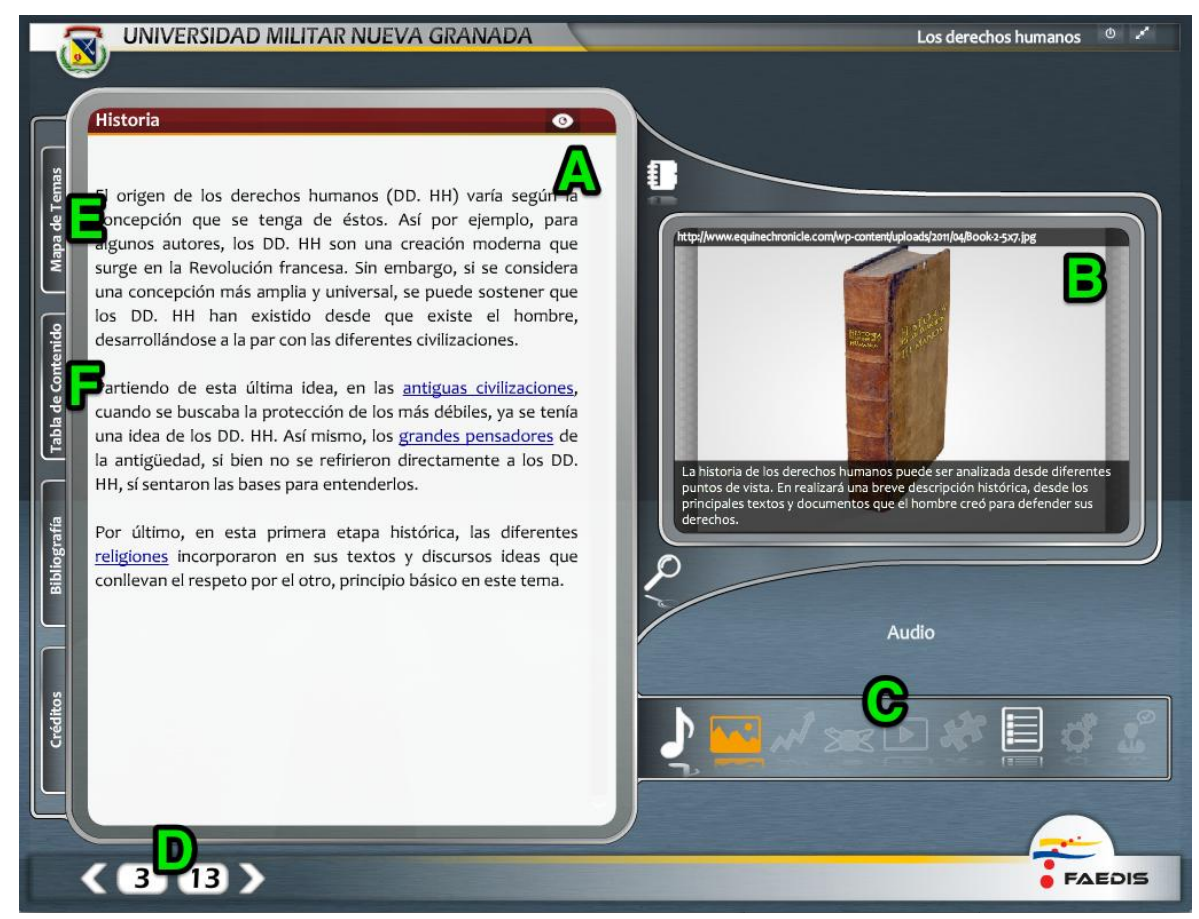

Figura 4. PLISE - Plataforma Interactiva de Software Educativo.

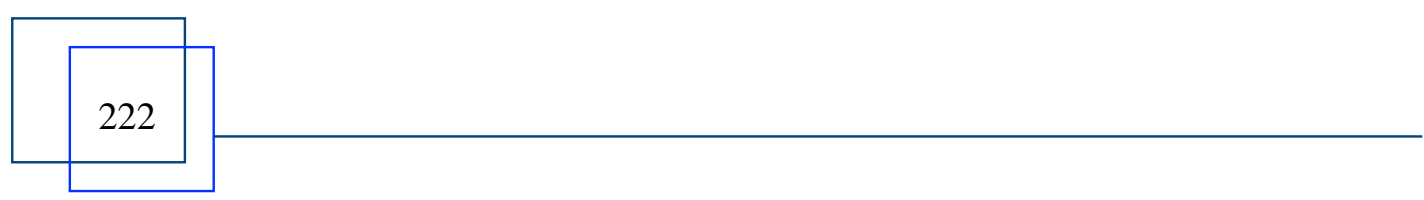




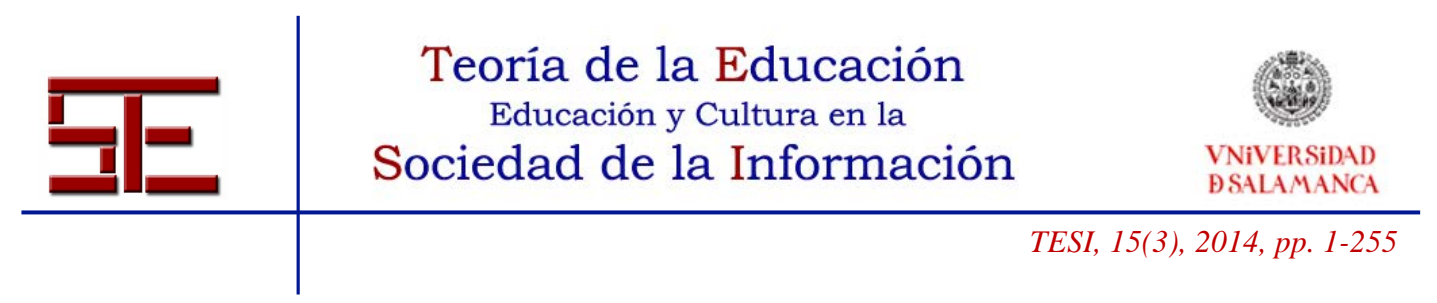

Existen otros componentes que integran, los cuales igualmente forman parte de la iniciativa interactiva de PLISE, solo que son activados en otros espacios del diseño, como las interactividades, que son componentes multimedia interactivos. Las actividades de repaso son otros módulos desarrollados en PLISE que presentan al estudiante actividades lúdicas. Las autoevaluaciones son actividades finales orientadas a preguntas cerradas para el repaso de los conceptos más importantes.

\subsection{Población objetivo de la prueba}

La población de estudiantes que vienen siendo los usuarios normales de esta herramienta pertenecen a las carreras de pregrado de la modalidad "A Distancia", entre las que se cuentan: administración de empresas, contaduría pública, relaciones internacionales, ingeniería civil, ingeniería industrial y administración de la seguridad. Sobre este grupo de usuarios, la herramienta de software PLISE, desde que se ha concebido como modelo de presentación de contenidos, ha venido siendo objeto de diferentes análisis que han implicado diversas actualizaciones y mejoras.

A raíz del impulso que se ha venido desarrollando en la universidad para capacitar a los docentes de planta en los contextos de utilización de TIC en la educación, para el presente estudio, se ha querido realizar un análisis sobre este grupo de usuarios que han desarrollado un curso de diplomado, el cual soportó la distribución de material de estudio con PLISE. Este programa fue desarrollado a lo largo del 2013, en diferentes cohortes entre marzo y agosto.

\subsection{Modelo de encuesta aplicada}

El principal instrumento utilizado de recogida de datos fue el cuestionario, a través del cual se pretendía comprender la percepción y uso que tienen los estudiantes objeto del estudio. La concepción de la encuesta se sustentó bajo la taxonomía propuesta por (Borges de Barros, 2002, p. 178), con el interés principal de evaluar aplicaciones multimedia en aspectos de calidad y de usabilidad en el aprendizaje.

Los principios planteados en esta taxonomía son los siguientes:

$\checkmark$ Principios semánticos, de los cuales se tienen en cuenta las características personales del usuario agrupando determinadas condiciones en donde la experiencia y la intuición son características que pueden influir en el diseño de aplicaciones multimedia. En la capacidad de la estructura cognitiva se tuvieron en cuenta: apariencia, densidad, asociación, veracidad, indicación y en cuanto al aprendizaje se tuvieron en cuenta aspectos relacionados con la instrucción como objetivos, test y actividades de aprendizaje.

$\checkmark$ Principios sintácticos, de los cuales se tienen en cuenta la capacidad operativa

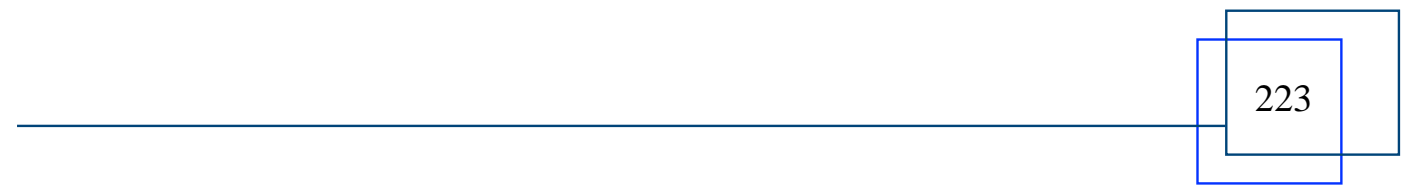




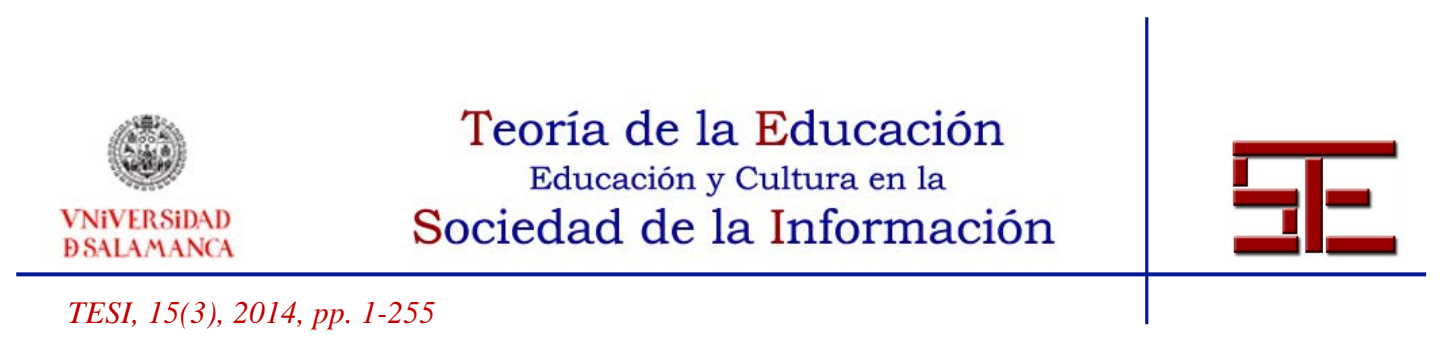

de la aplicación: características de gestión del error, funcionamiento, tiempo de respuesta y la capacidad de distribución de la aplicación multimedia: portabilidad, mantenimiento y adaptabilidad.

$\checkmark$ Principios híbridos, de los cuales se tienen en cuenta la capacidad operativa de la aplicación multimedia: desempeño y predicción, y en la capacidad de la estructura cognitiva: legibilidad, organización, consistencia, desempeño, precisión, propiedad de ser completo.

Además de estos principios, se agregaron otros aspectos complementarios relacionados con el contenido presentado, en términos de la pertinencia, organización, estructura y la importancia del uso de medios en el aprendizaje más otros aspectos orientados al uso de móviles y sugerencias y recomendaciones.

Tomando como base este modelo y los criterios de valoración sugeridos, se diseñó la encuesta con 35 preguntas organizadas en cinco secciones, así:

1. Perfil del usuario: pretende realizar una caracterización del usuario y algunos aspectos relacionados con el acceso a Internet y dispositivos usados para acceder a un Sistema de Administración de Aprendizaje - LMS.

2. Funcionamiento y manejo de la aplicación: valida aspectos de descarga, ejecución y navegación.

3. Apariencia y distribución de contenido del software: recoge aspectos relacionados con la organización de componentes gráficos, organización de los contenidos y presentación de textos.

4. Didáctica utilizada en la herramienta: analiza las herramientas de interacción, de evaluación y de los contenidos presentados.

5. Retroalimentación final: cuestiona aspectos de uso del producto y consideraciones para mejorar el producto diseñado.

El cuestionario era de carácter anónimo, voluntario y fue aplicado una vez terminado el curso. Las preguntas combinaron escalas tipo Linkert y preguntas abiertas. Fue distribuido en forma virtual a los correos institucionales de todos los estudiantes, a través de un formulario en Google Docs.

\subsection{Descripción de la investigación}

Las implicaciones en la elaboración de material de estudio, por un lado necesariamente deben estar fundamentados en aspectos pedagógicos y por el otro con parámetros relacionados a la forma en cómo se presentan en pantalla, los contenidos y la usabilidad de la aplicación que los pone en escena.

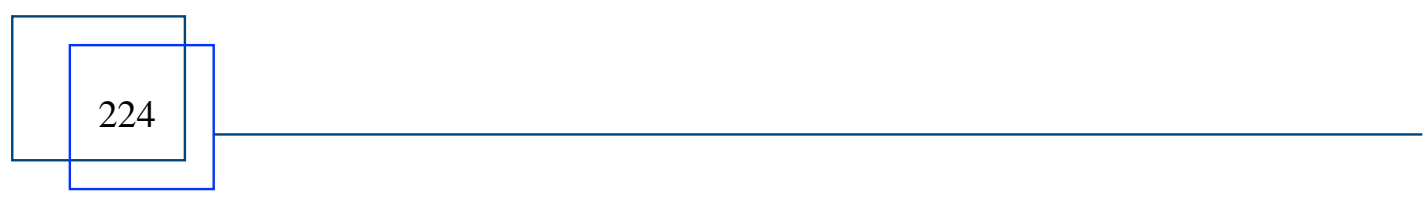




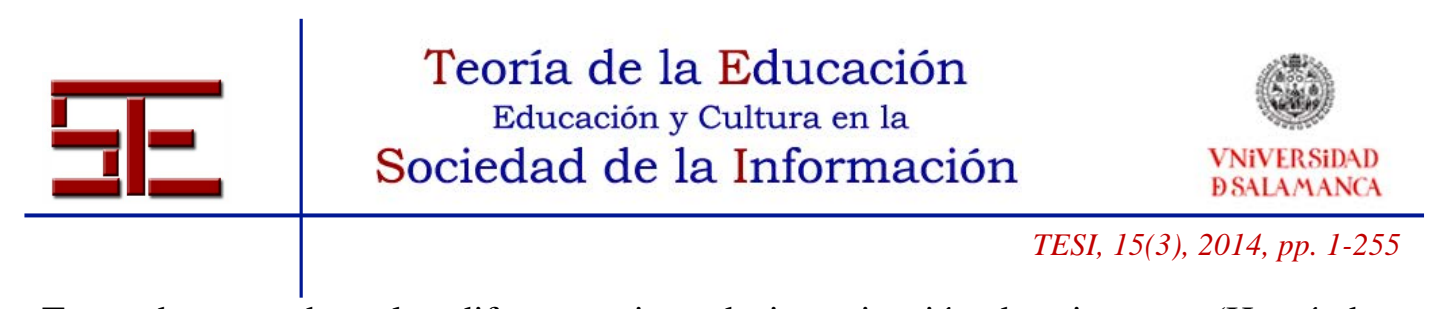

Tomando como base los diferentes tipos de investigación descritos por (Hernández, 1991, p. 71), el tipo de investigación utilizado en el proyecto actual corresponde a un estudio descriptivo, cuyo propósito es poder identificar diversos aspectos relacionados con la usabilidad del producto de software descrito en el numeral 2.1, buscando especificar sus propiedades y características más importantes. A través del instrumento de recolección de datos descrito anteriormente, se buscará medir y evaluar aquellos aspectos de funcionamiento de PLISE, esencialmente los relacionados con las normas ISO 14915-1 y los principios de diseño de aplicaciones multimedia propuestos por (Bauzá, 1997).

\section{EVALUACIÓN DE RESULTADOS}

De una población aproximada de 200 docentes que efectivamente desarrollaron el curso de diplomado, un $16.5 \%$ atendió el llamado a la encuesta aplicada, es decir que se obtuvieron un total de 33 respuestas.

En la figura 5, se muestra la distribución de la población encuestada, en donde docentes con formación de maestría predominaron en la prueba con un $61 \%$, siguiéndole un porcentaje menor con el $18 \%$ de docentes con formación de especialización y un $12 \%$ de doctorado.

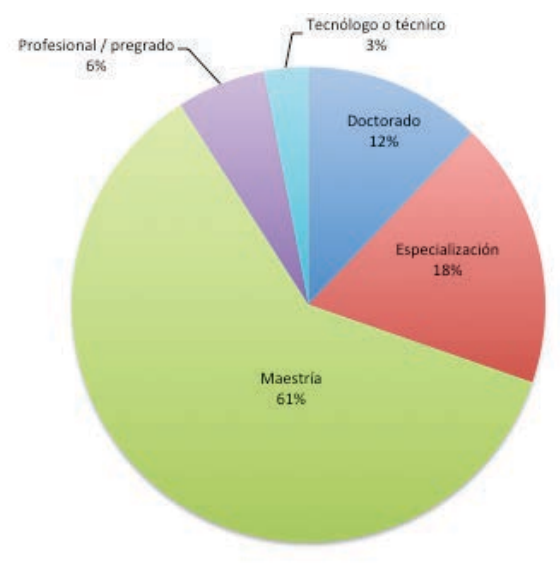

Figura 5. Población objetivo de la prueba.

A la luz de los datos recogidos, se ha podido observar en términos generales que los usuarios valoran la aplicación como una herramienta muy útil para efectos de la presentación y distribución de contenidos multimedia.

En la figura 6, se presenta el resumen de la valoración que han realizado los estudiantes en cada uno de los principios de la taxonomía implementados en la encuesta. Todas las preguntas fueron clasificadas bajo los principios semánticos, sintácticos e híbridos.

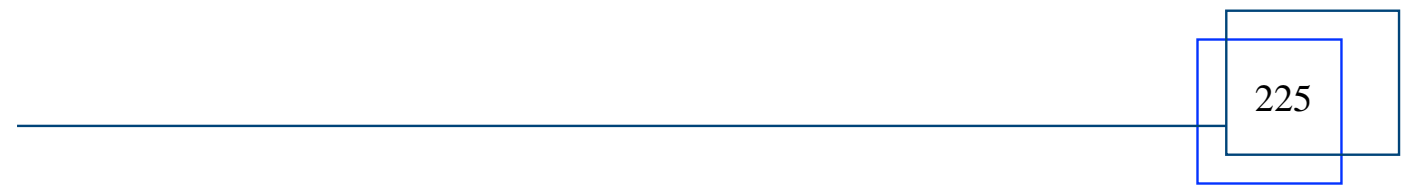




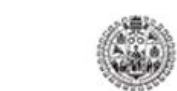

VNiVERSIDAD

DSALAMANCA

TESI, 15(3), 2014, pp. 1-255
Teoría de la Educación

Educación y Cultura en la Sociedad de la Información

Luego se realizaron las sumatorias por cada ítem de la escala de Linkert. Se puede observar, en términos generales, que la tendencia para todos los principios es estar "Parcialmente de acuerdo" y "De acuerdo".

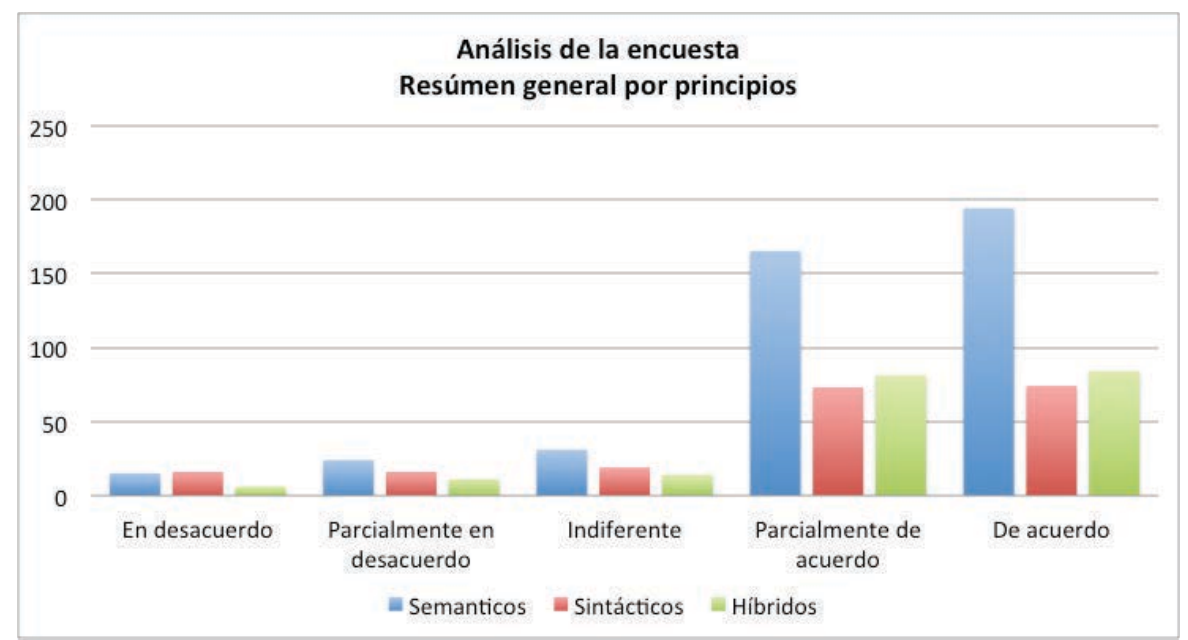

Figura 6. Resultados de la encuesta de análisis.

Tomando como base las 13 preguntas categorizadas bajo los principios semánticos, el $83 \%$ se distribuyen en las opciones "De acuerdo" y "Parcialmente de acuerdo", lo cual implica que la organización de los componentes gráficos de la interfaz, las herramientas de interacción y de evaluación, cumplen con su función sustantiva.

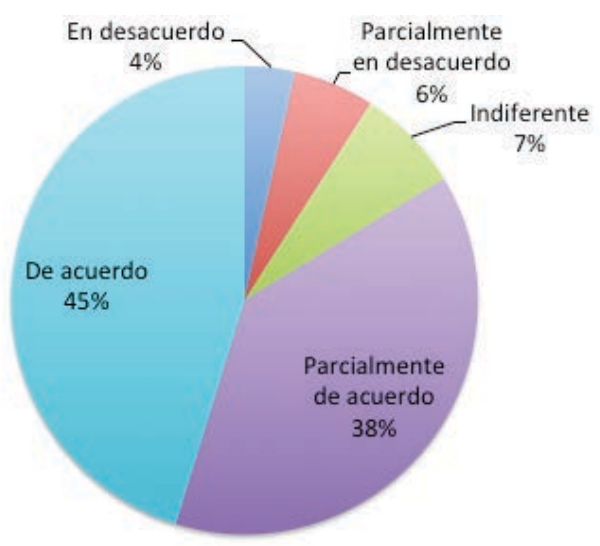

Figura 7. Respuestas relacionadas con los principios semánticos.

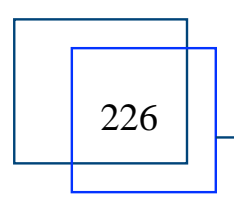




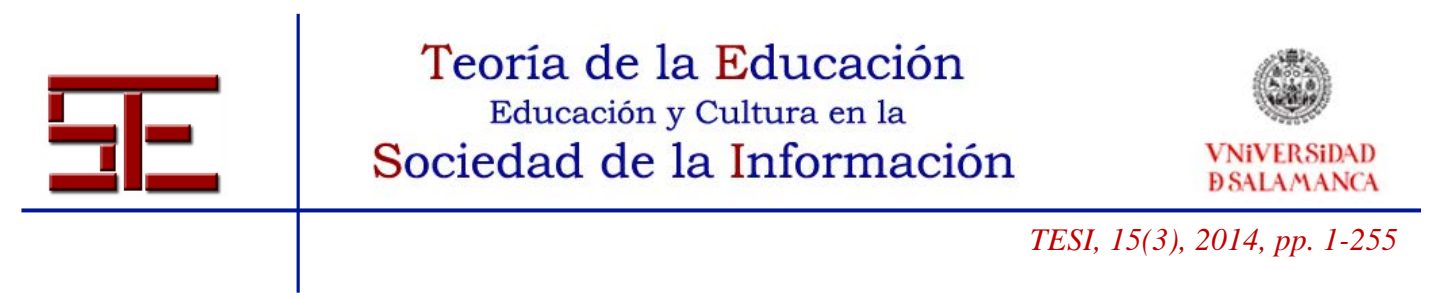

Bajo los principios sintácticos, aspectos analizados como la descarga los archivos desde el Aula Virtual, visualización de contenidos en pantalla y rendimiento en el computador, permite sugerir que hay un casi $30 \%$ (en desacuerdo, parcialmente en desacuerdo e indiferente) que seguramente tuvieron algún tipo de inconvenientes técnicos, que hay que revisar.

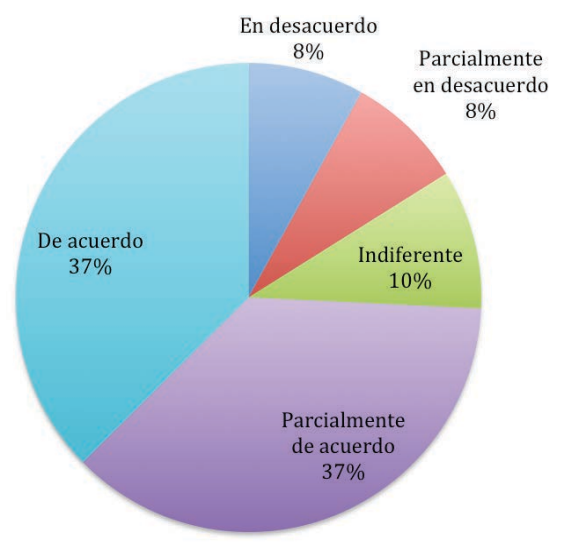

Figura 8. Respuestas relacionadas con los principios sintácticos.

Con relación a los principios híbridos, los aspectos que se analizaron se relacionan con la navegación en la herramienta mientras estudia, memoria de pantalla estudiada, búsqueda de información como material de referencia, ayuda al usuario y tamaño de la fuente adecuada a la lectura. El $83 \%$ manifestó la aceptación que estas características favorecieron de alguna forma, el proceso de estudio.

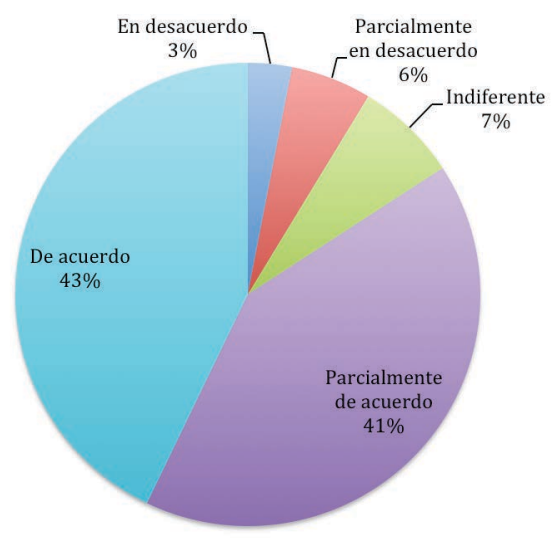

Figura 9. Respuestas relacionadas con los principios híbridos.

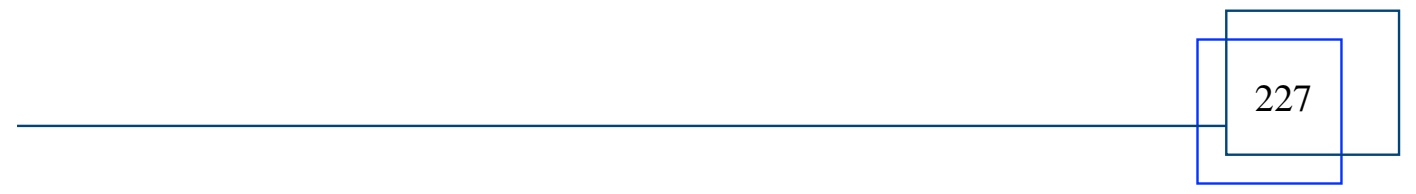




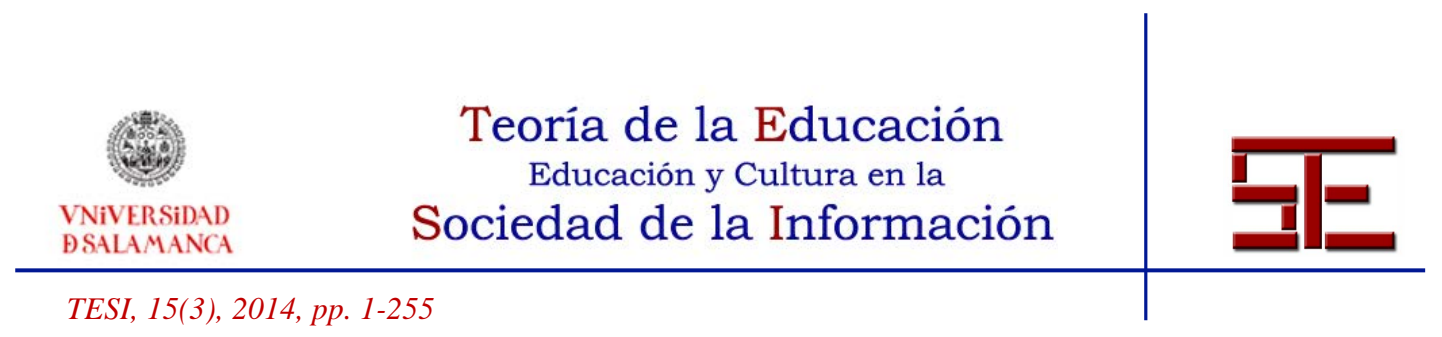

En la Tabla 2, se muestra un análisis realizado condensado, tomando como base los lineamientos planteados en la primera parte de la norma ISO 14915.

\begin{tabular}{|c|c|}
\hline Principios de la norma & Análisis de cumplimiento \\
\hline $\begin{array}{l}\text { Los diversos componentes gráficos } \\
\text { interactivos, como botones o enlaces, } \\
\text { contienen una descripción corta de su acción. }\end{array}$ & \multirow[t]{2}{*}{$\begin{array}{l}\text { Cumple en un } 83 \% \text {, según los principios } \\
\text { semánticos, luego de promediar las } \\
\text { respuestas correspondientes a esta } \\
\text { categoría. }\end{array}$} \\
\hline $\begin{array}{l}\text { Los elementos de control para reproducir o } \\
\text { detener un medio, funcionan de la misma } \\
\text { manera en todos los vídeos y animaciones de } \\
\text { una aplicación multimedia. }\end{array}$ & \\
\hline $\begin{array}{l}\text { En la aplicación multimedia, se suministra } \\
\text { una representación visual de la estructura de } \\
\text { navegación. }\end{array}$ & $\begin{array}{l}\text { De acuerdo a las respuestas de una } \\
\text { pregunta en particular, un } 84 \% \text { responde } \\
\text { que están de acuerdo y parcialmente de } \\
\text { acuerdo. }\end{array}$ \\
\hline $\begin{array}{l}\text { Se usa un contraste suficiente para el fondo } \\
\text { de la pantalla, así como un conjunto de } \\
\text { botones de navegación que puedan ser } \\
\text { fácilmente detectados por el usuario. }\end{array}$ & $\begin{array}{l}\text { El } 87 \% \text { de las respuestas relacionadas a } \\
\text { este principio están de acuerdo y } \\
\text { parcialmente de acuerdo. }\end{array}$ \\
\hline $\begin{array}{l}\text { Es conveniente que la aplicación facilite } \\
\text { siempre al usuario la ubicación de su } \\
\text { posición actual, así como su punto de partida } \\
\text { y hacia dónde dirigirse desde ese punto. }\end{array}$ & $\begin{array}{l}\text { Se tiene un acierto del } 79 \% \text {, según los } \\
\text { principios sintácticos. Se resalta que } \\
\text { para el } 13 \% \text { le es indiferente esta } \\
\text { característica. }\end{array}$ \\
\hline $\begin{array}{l}\text { Es conveniente que la navegación se pueda } \\
\text { efectuar de forma coherente y transparente. }\end{array}$ & $\begin{array}{l}\text { El } 92 \% \text { ha respondido acertadamente en } \\
\text { esta característica, según la categoría de } \\
\text { Principios híbridos. }\end{array}$ \\
\hline $\begin{array}{l}\text { Conviene suministrar al usuario diferentes } \\
\text { posibilidades para conseguir la información } \\
\text { deseada. } \\
\text { Es conveniente que el contenido esté } \\
\text { organizado teniendo en cuenta los límites del } \\
\text { proceso de información del ser humano, de }\end{array}$ & $\begin{array}{l}\text { La categoría de Principios híbridos, } \\
\text { permite evaluar estos aspectos, con un } \\
92 \% \text { de acierto en promedio. }\end{array}$ \\
\hline
\end{tabular}

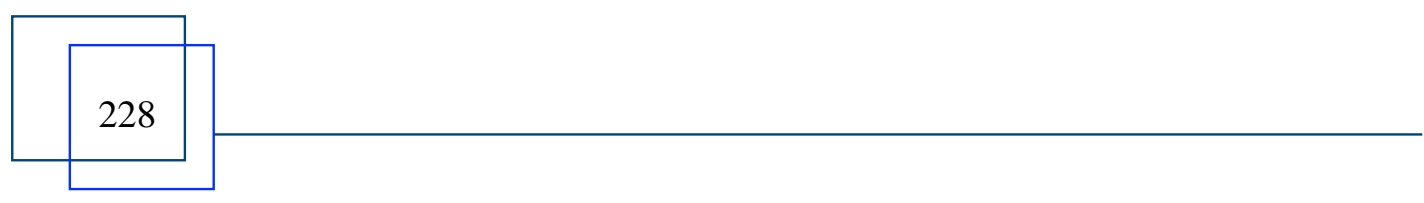




\begin{tabular}{|c|c|c|c|}
\hline$=$ & \multicolumn{2}{|c|}{$\begin{array}{l}\text { Teoría de la Educación } \\
\text { Educación y Cultura en la } \\
\text { Sociedad de la Información }\end{array}$} & 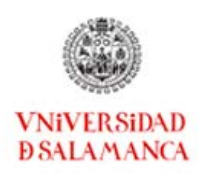 \\
\hline & \multicolumn{3}{|c|}{ TESI, 15(3), 2014, pp. 1-255 } \\
\hline \multicolumn{4}{|c|}{$\begin{array}{l}\text { forma que los usuarios puedan identificar } \\
\text { fácilmente las partes del contenido y sus } \\
\text { relaciones entre sí. }\end{array}$} \\
\hline \multicolumn{2}{|c|}{$\begin{array}{l}\text { Es conveniente que la aplicación multimedia } \\
\text { esté diseñada para atraer al usuario, es decir, } \\
\text { lograr su atención y motivarlo para que } \\
\text { interactúe con ella. }\end{array}$} & \multicolumn{2}{|c|}{$\begin{array}{l}\text { Se puede considerar que PLISE es una } \\
\text { herramienta útil para apoyar los } \\
\text { procesos de estudio, debido a que se } \\
\text { obtuvo un } 89 \% \text { de acierto, en las } \\
\text { conclusiones generales de la encuesta. }\end{array}$} \\
\hline
\end{tabular}

Tabla 2. Cuadro descriptivo de resultados del análisis de la encuesta aplicada.

Otros aspectos de la norma ISO 14915 se entienden que se cumplen, ya que corresponden a aspectos inherentes a los contenidos propios presentados en PLISE y que al analizar los procedimientos de calidad en la producción de contenidos, esta evaluación fue aplicada en una Institución de educación superior en Colombia - Bogotá de la Universidad Militar Nueva Granada con base a los estándares establecidos en educación a distancia por la misma (SGC, INSEDI-P-002, 2009), se encuentran actividades explícitas que referencian la selección de autores, capacitación a los mismos, elaboración y revisión de un módulo para educación a distancia y control de calidad.

Los principios a que se refiere la norma en este punto, son:

$\checkmark$ Conviene que el usuario no sea sometido a una sobrecarga de información. Es conveniente que los medios sean elegidos y presentados de forma que el usuario disponga de tiempo suficiente para comprender la información proporcionada por el medio.

$\checkmark$ Conviene que el diseño, la selección y la combinación de los medios favorezcan la comprensión por el usuario de la información transmitida.

$\checkmark$ Conviene que se suministre a los usuarios diferentes combinaciones de medios que presenten el mismo contenido.

$\checkmark$ El diseño de los materiales de estudio debe tener en cuenta los objetivos de comunicación, con objeto de orientar el desarrollo o la selección de este contenido, su estructura, su tipo y sus adecuadas representaciones.

$\checkmark$ El diseño de la estructura de los materiales de estudio, debe comprender la especificación de las diferentes partes de ese contenido y sus interrelaciones, mediante el uso de las técnicas apropiadas, tales como sinopsis, guiones, gráficos u otras formas de presentar la información.

$\checkmark$ Facilitar la percepción de componentes gráficos contrastando adecuadamente el manejo del color. 


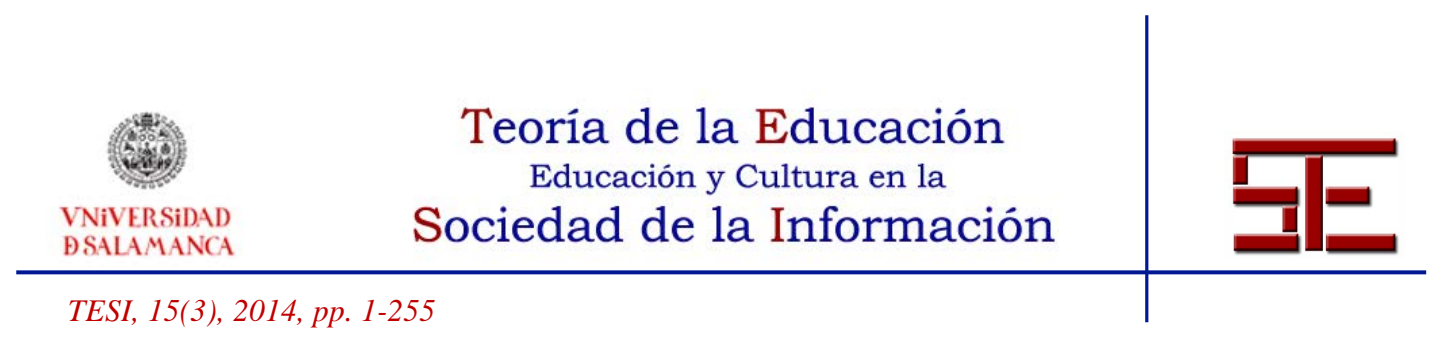

$\checkmark$ Una estructura teórica compleja puede ser explicada a través de diversos medios para facilitar al estudiante la comprensión del tema.

$\checkmark$ La explicación narrada de los componentes multimedia se orienta a transmitir la información relevante para facilitar el aprendizaje.

\section{CONCLUSIONES}

El análisis de los datos obtenidos a través de la plataforma multimedia interactiva en materia de diseño de interfaces multimedia se ajusta a los parámetros de calidad evaluados, lo que implica que la herramienta implementada y utilizada está cumpliendo con los propósitos para los cuales fue creada. Los usuarios han manifestado estar de acuerdo con la utilidad de PLISE en procesos de estudio y que la continuarían utilizando para acceder a los materiales. Es un producto que debe ser permanentemente revisado y actualizado, esto se debe principalmente a los cambios tecnológicos que pueden ser aplicados a procesos educativos. Uno de los resultados observados en la encuesta en la retroalimentación final, los usuarios sugieren la importancia de poder acceder a contenidos desde dispositivos móviles.

Es importante mantener en el proceso de producción de material académico la fundamentación en principios de orden pedagógico y didáctico, que dinamicen, impulsen y motiven el aprendizaje. Se pueden diseñar y ofrecer herramientas tecnológicas con altos niveles de estandarización, sin embargo aquellos aspectos pedagógicos sobresalen a cualquier tecnología que sea aplicada. Las actividades interactivas deben ser incrementadas por sugerencia de los usuarios, esto conlleva a implementar estrategias pedagógicas en el desarrollo de estas actividades donde permitan al usuario aprender.

Por medio de esta Plataforma PLISE se puede diseñar un banco de objetos de aprendizaje, que sirva de base para las asignaturas impartidas tanto en programas presenciales como virtuales. Podrá considerarse entonces como una excelente estrategia para fundamentar los programas académicos con base tecnológica y así dar un paso fuerte hacia modelos de internacionalización que busca la Universidad.

Los modelos de evaluación implementados aportan información para el seguimiento y control del contenido y el medio de visualización. Como este trabajo se ha centrado en la valoración de la herramienta PLISE como instrumento para presentar contenidos de estudio, se recomienda desarrollar un análisis complementario que permita evaluar la pertinencia de los contenidos desarrollados y su significancia en los procesos de aprendizaje, frente a metodologías de estudio sin apoyo de estos recursos tecnológicos.

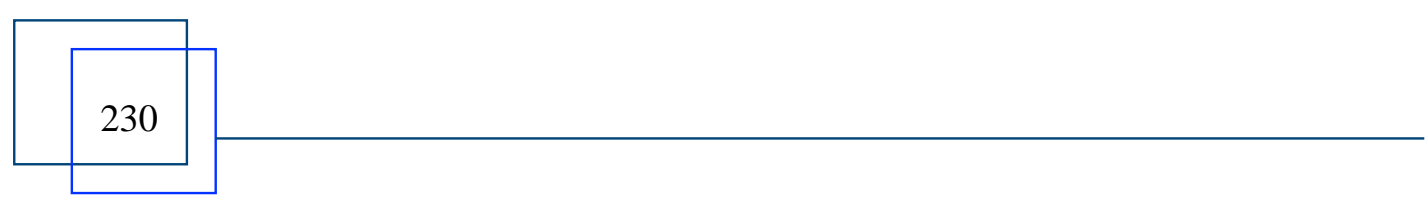




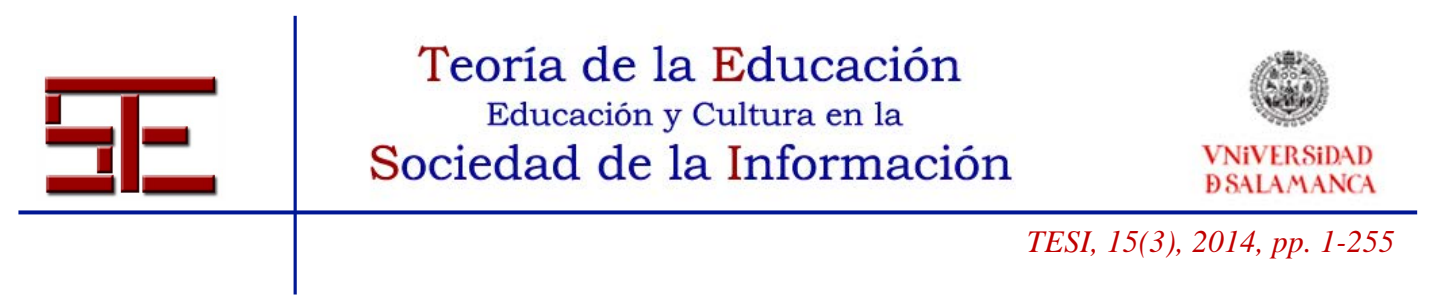

\section{BIBLIOGRAFÍA}

America Learning Media. (2010). Amplia incorporación del e-learning en universidades latinoamericanas. Extraído el 30 enero, 2014 de $<$ http://www.americalearningmedia.com/component/content/article/24-indicadores/82amplia-incorporacion-del-e-learning-en-universidades-latinoamericanas $>$.

Bauzá, G. (1997). El guión multimedia. Producción de aplicaciones multimedia, (pp. 73-90), Anaya Multimedia.

Borges de Barros, H. (2002). Análisis experimental de los criterios de evaluación de usabilidad de aplicaciones multimedia en entornos de educación y formación a distancia. Barcelona: UPC. Consultado en: <http://hdl.handle.net/10803/6542〉.

Bevan, N. (1999). Quality in Use: Meeting User Needs for Quality. Journal of System and Software.

Bevan, N. (2006). International standards for HCI. Basado en un capítulo de la enciclopedia de Human Computer Interaction, Ideal Group.

Brunner, José Joaquín \& Tedesco, Juan Carlos. 2003. Las Nuevas Tecnologías y el Futuro de la Educación. UNESCO. Recuperado de <http://unesdoc.unesco.org/images/0014/001423/142329so.pdf>.

Duart, J., \& Lupiáñez, F. (2005). Procesos institucionales de gestión de calidad del elearning en instituciones educativas. Extraído el 30 enero, 2014 de <http://www.mineducacion.gov.co/1621/articles-85679_Archivo_pdf.pdf〉.

Hernández Sampieri, R. (1991). Metodología de la investigación (Primera edición.). McGraw Hill.

ICONTEC, ISO 14915. (2002). Software ergonomics for multimedia user interfaces (Vol. 1). (ICONTEC, Ed.). Switzerland: ISO.

Jaramillo, J. (2013). Usabilidad del software de presentación de contenidos educativos de la Facultad de Educación a Distancia. Obtenido de 〈http://goo.gl/qLDbIA>.

Nova, J., Jaramillo, J. \& Quintero, C. (2012). Framework for collaborative construction of virtual learning objects, Applied Computing 2012.

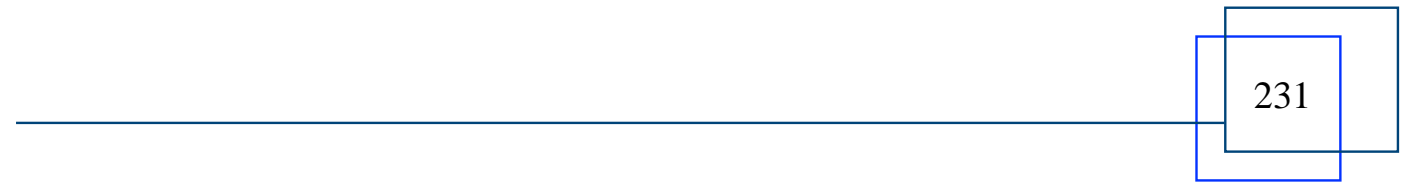




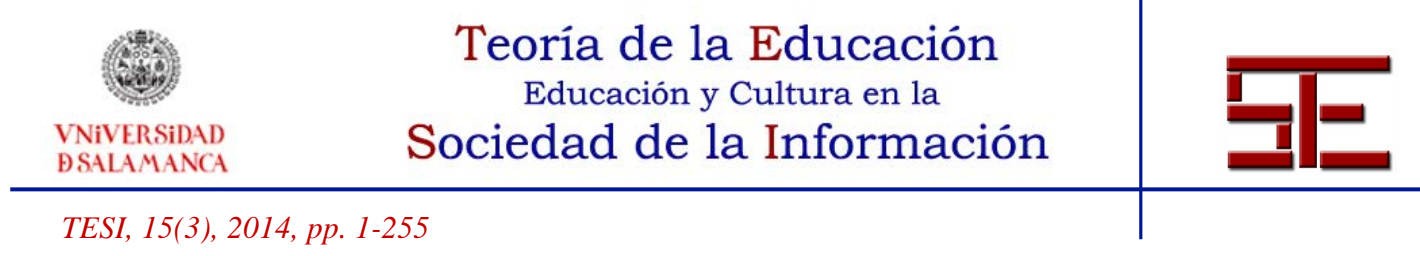

Nielsen, J., (1993). Usability Engineering. Academic press, Inc. <http://books.google.com.co/books?id=DBOowF7LqIQC\&lpg=PP1\&ots=Bj99WSEXA $\mathrm{V} \& \mathrm{dq}=\mathrm{jakob} \% 20$ nielsen\%20usability\%20principles\&lr\&hl=es\&pg=PA25\#v=onepage $\& \mathrm{q} \& \mathrm{f}=$ false $>$.

SGC, INSEDI-P-002. (2009). Procedimiento producción de material académico de educación a distancia. Documento institucional, Universidad Militar Nueva Granada, División de calidad, Bogotá-Colombia.

Tullis, T., \& Albert, B. (2008). Measuring the user experience (Vol. 1). Burlington: Morgan Kaufmann.

Vos, T. (2005). Usabilidad de las aplicaciones informáticas. Revista del Instituto Tecnológico de Informática, 8, 11-17. 